\title{
Kinetic studies on sex difference in susceptibility to chronic benzene intoxication- with special reference to body fat content
}

\author{
AKIO SATO, TAMIE NAKAJIMA, YUKIKO FUJIWARA, and NINZO MURAYAMA \\ Department of Hygiene, Shinshu University Faculty of Medicine, Matsumoto, Japan
}

\begin{abstract}
Sato, A., Nakajima, T., Fujiwara, Y., and Murayama, N. (1975). British Journal of Industrial Medicine, 32, 321-328. Kinetic studies on sex difference in susceptibility to chronic benzene intoxication-with special reference to body fat content. The sex difference in the susceptibility to haematopoietic disorders induced by benzene was studied kinetically with a special reference to its relation with the body fat content. In rats of both sexes with a large body fat content, benzene was eliminated more slowly and remained in the body for a longer time than in rats with a small body fat content. In accord with this finding, the decrease in white blood cell numbers during a chronic benzene exposure was observed only in the groups of rats which had a large volume of fat tissue. In an experimental human exposure, the elimination of benzene was slower in the females than in the males. The kinetic study revealed that the slower elimination in the females is due primarily to the bulky distribution of body fat tissue in that sex. From these results obtained from the experimental exposure of men and rats to benzene, it was concluded that the human female, with her massive body fat tissue, shows an inherent disposition to be susceptible to a chemical such as benzene which has a high affinity with fat tissue.
\end{abstract}

It has been widely believed that the female has a higher degree of susceptibility than the male to haematopoietic disorders induced by benzene (Browning, 1965). This sex difference has been reported not only in such laboratory animals as 1ats (Ikeda, 1964) and rabbits (Hirokawa, 1955), but also in human beings (Hirokawa, 1960).

There has been, however, no satisfactory explanation for the mechanism by which the sex difference manifests itself. Some paid attention in the study using rats to the sex difference observed in the detoxication mechanism of benzene (Ikeda, 1964). Others attached importance to the action of follicular hormone in the experiment with rabbits (Hirokawa, 1955). It is, however, doubtful whether what was inferred in laboratory animals is directly applicable to human beings.

Since the toxic effect of a foreign chemical is related to its concentration at the site of action (Levy and Gibaldi, 1972), the sex difference in the susceptibility, if any, should largely be attributed to the difference between the concentration of the toxic agent at the site of action attained in the male and in the female (Quinn, Axelrod, and Brodie, 1958), which in turn is controlled by such processes in the living body as absorption, distribution, excretion, and metabolism of the chemical.

From kinetic studies using a mathematical model, Sato et al. (1974) showed that fat tissue plays a very important role in the processes of absorption, distribution, and elimination of organic solvent vapours such as benzene and toluene which have a high affinity to that tissue. Hence they suggested that the occurrence of intoxication by these chemicals would be related to the body fat content.

In human beings, the body fat content is larger on average in the female than in the male (Keys and Brožek, 1953). Accordingly, it seems not unreason- 
able to suppose that the higher susceptibility in the female to a long-term exposure of benzene would be related to the massive distribution of fat tissue in that sex.

The present paper deals with kinetic studies carried out experimentally on both human subjects and rats to clarify the significance of fat tissue in manifesting the sex difference in the susceptibility to the myelotoxic action of benzene.

\section{Methods}

\section{Experimental studies with rats}

Animals Altogether 20 Wistar strain rats, 90 days old, consisting of 10 males and 10 females, were used. They were divided into four groups which were denoted as FM, FF, LM, and LF group, respectively. Each group consisted of five rats of the same sex. Both FM (fat male) and FF (fat female) groups were allowed to take pelleted feed (Nippon Clea, Type CE-2) and water ad libitum. The other two groups, LM (lean male) and LF (lean female), were allowed to drink water ad libitum, but were fed with a restricted amount of the feed, $20 \mathrm{~g} /$ day. Upon being fed in this way for a month, all four groups were then exposed to $1000 \mathrm{ppm}$ benzene daily for two hours $(9.00-11.00 \mathrm{am})$ over a period of 12 weeks, with the same feeding conditions being maintained throughout.

Exposure chamber The air for the exposure which contains $1000 \mathrm{ppm}$ benzene was prepared by injecting liquid benzene into a metered air stream at a known rate by means of a power-driven syringe (Hanson, Reilly, and Stagg, 1965). The air stream was then led into a preliminary chamber where the vapour was mixed thoroughly, and hence into the exposure chamber. This continuous aeration was to maintain the aimed concentration, 1000 ppm benzene. The atmospheric concentration was monitored with a gas chromatograph every 20 minutes while exposing.

The exposure was done as follows: a calculated amount of benzene was first injected into the exposure chamber where the rat had been placed, vaporized and mixed homogeneously with a motor-fan, in order to achieve a rapid build-up to the required concentration. Several minutes after the injection when the concentration reached the required level, the air issuing from the preliminary chamber was introduced into the exposure chamber through an air tube.

Blood level of benzene and blood cell counts Blood concentration of benzene and blood cell numbers (red and white blood cell) were determined at intervals of one week with blood samples obtained preceding the daily exposure (8.30-9.00 am; about 22 hours after the cessation of the exposure on the previous day), when $0.02 \mathrm{ml}$ blood was collected with a Sahli's pipette from a small cut made on the tail end of rats. With this sample, the blood level of bezene was determined by the gas chromatographic equilibration method (Sato, Nakajima, and Fujiwara, 1975). Red and white blood cell numbers were counted by means of an automatic blood cell counter (Toa, microcellcounter) with another blood sample similarly obtained.
When the first day's exposure was over, the blood level of benzene was determined repeatedly at intervals of one hour to observe the time-course of disappearance of the absorbed benzene.

Estimation of body fat content Upon completion of the last day's experiment all the rats were killed and weighed. Then the volume of the whole body of each rat was estimated by measuring the volume of water replaced by the body. The body fat content was calculated from the body weight and volume according to the method of Ruthbun and Pace (1945).

\section{Experimental human exposure to benzene}

Five men and five women weighing 60.4 and $55.4 \mathrm{~kg}$ on the average/ respectively, served as volunteers for experimental exposure; they were all Japanese medical students, 21 to 24 years old. They were allowed to inhale $25 \mathrm{ppm}$ of benzene for two hours in a sitting position. The air inhaled was prepared by the same method as in the exposure of rats. The inhalation was carried out through a breathing mask equipped with a non-rebreathing valve. After the inhalation was over, the volunteers kept resting in the same sitting position. At predetermined intervals during and after the inhalation $1.0 \mathrm{ml}$ blood from the cubital vein, and about $100 \mathrm{ml}$ end-tidal air were taken to determine benzene concentration in these materials: the blood level of benzene was determined by the gas chromatographic equilibration method (Sato, 1971; Sato et al., 1975); the concentration in the expired air was determined by introducing a portion of the sampled air directly into a gas chromatograph (Sato, 1968).

The results of both the saturation and desaturation processes of benzene in the body were submitted to kinetic analysis using the method of Sato et al. (1974).

\section{Results}

\section{Experimental results with rats}

Body weight of rats Body weight increased considerably as expected in the FM and FF groups, reaching 430 and $280 \mathrm{~g}$, respectively, while the body weight of LM and LF groups failed to surpass 230 and $200 \mathrm{~g}$, respectively, at the time of the first exposure. After the exposure had started, the body weight decreased temporarily in all the four groups. A marked and sustained drop in body weight which was maintained over several weeks was observed exclusively in the FM and FF groups. In the female rats, the body weight gain on average over the scheduled exposure of 12 weeks was more pronounced in the LF than in the FF group, in spite of the restricted amount of feed for the LF. For example, the difference of body weight between the FF and LF diminished from 80 to $30 \mathrm{~g}$ in this period (Fig. 1).

Body fat content The Table summarizes the body fat content estimated when the scheduled exposure was over, as well as the body weight measured at the 


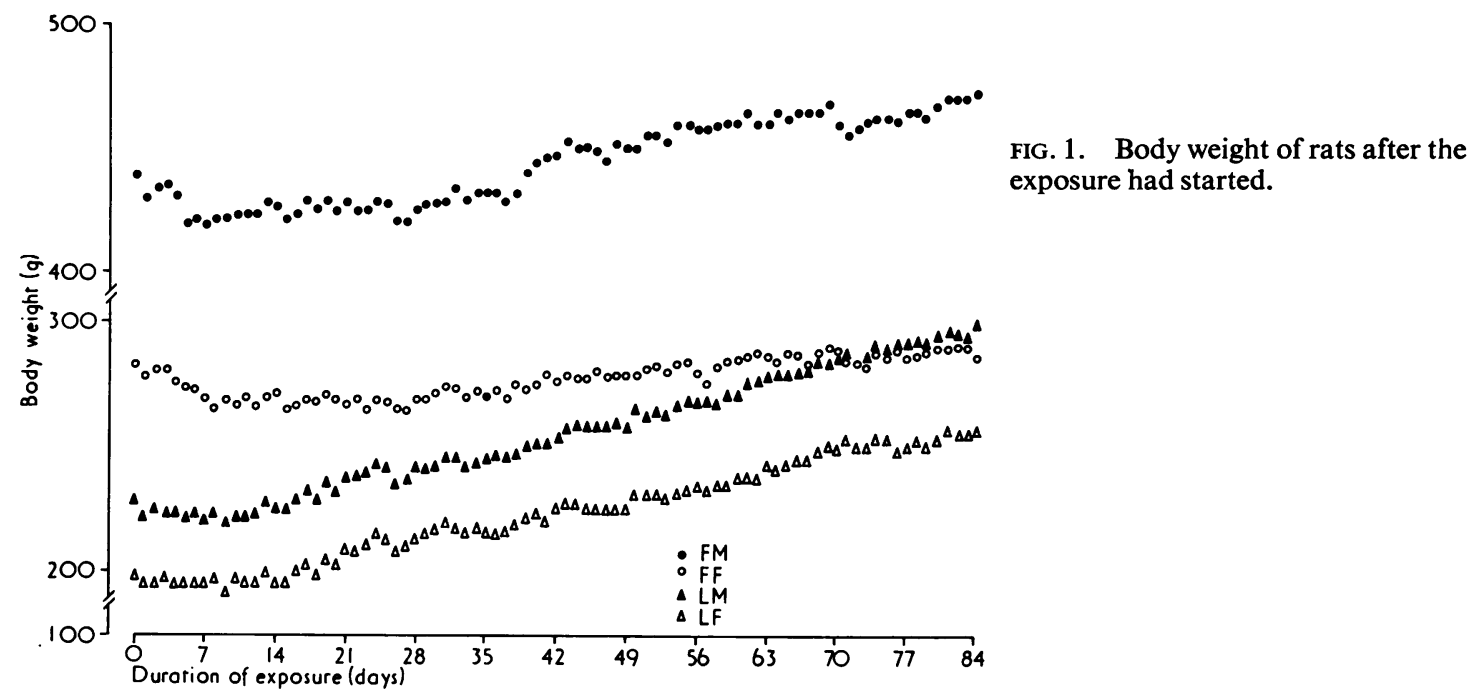

TABLE Body Fat Content

\begin{tabular}{c|c|c}
\hline Group & Body weight $($ grams $)$ & Fat content $($ grams $)$ \\
\hline FM & $474 \cdot 0 \pm 10 \cdot 1$ & $147 \cdot 8 \pm 11 \cdot 5$ \\
FF & $287 \cdot 0 \pm 18 \cdot 1$ & $66 \cdot 4 \pm 10 \cdot 1$ \\
LM & $301 \cdot 4 \pm 9 \cdot 6$ & $29 \cdot 5 \pm 8 \cdot 6$ \\
LF & $256.6 \pm 16 \cdot 8$ & $38 \cdot 0 \pm 8 \cdot 3$ \\
\hline
\end{tabular}

Figures in the table are mean $\pm \operatorname{SD}(n=5)$

same time. The body fat contents of the four groups were in decreasing order as follows:

$$
\text { FM } \gg \text { FF }>\text { LF } \doteqdot \text { LM }
$$

There were statistically significant differences between the FM and LM groups $(P<0.001)$ and between the FF and LF groups $(P<0.005)$.

Concentration of benzene in blood Elimination curves obtained from the four groups with the exposure to $1000 \mathrm{ppm}$ of benzene for two hours are shown in Fig. 2. The analysis of covariance (Snedecor, 1956) revealed that the rate of disappearance of benzene was significantly lower in the FM than in the LM $(P<0.01)$ and also in the FF than in the LF $(P<0.05)$.

The concentrations of benzene in blood determined weekly immediately before the daily exposure are shown in Fig. 3. The blood levels fluctuated considerably in all the groups, and there was a general tendency for the fluctuations to vary in the order of FF $>$ FM $>$ LM $\doteqdot$ LF.

These results indicate that, in the groups with a large body fat content, the absorbed benzene tended to disappear from blood slowly and remain in the body for a considerably long time.

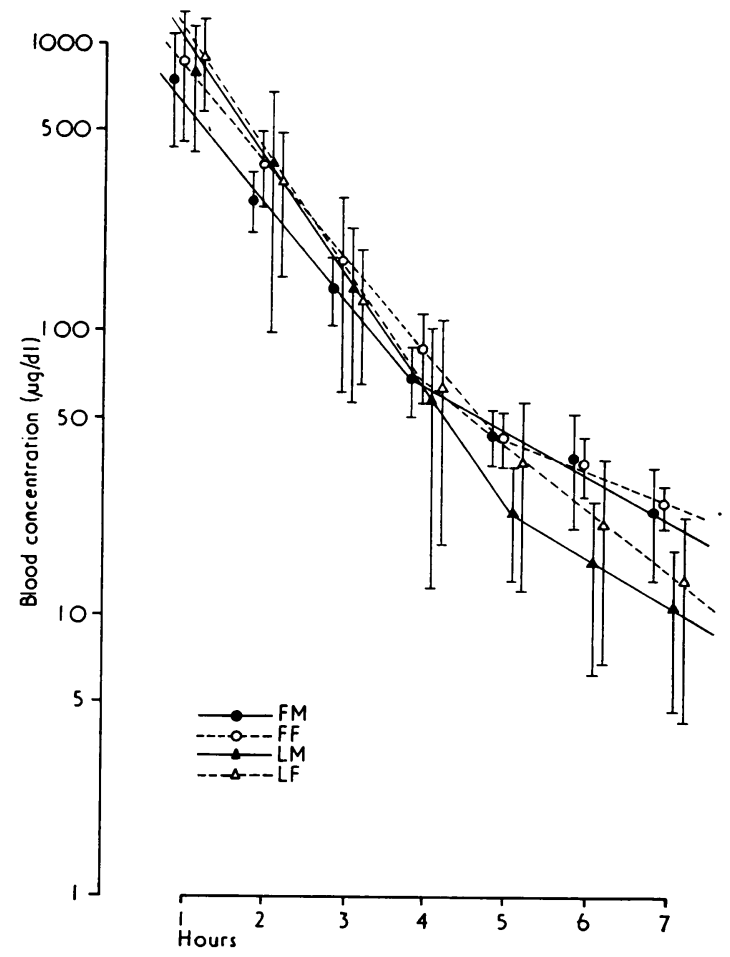

FIG. 2. Elimination curves of benzene obtained with rats. The vertical line represents the mean value \pm SD. 


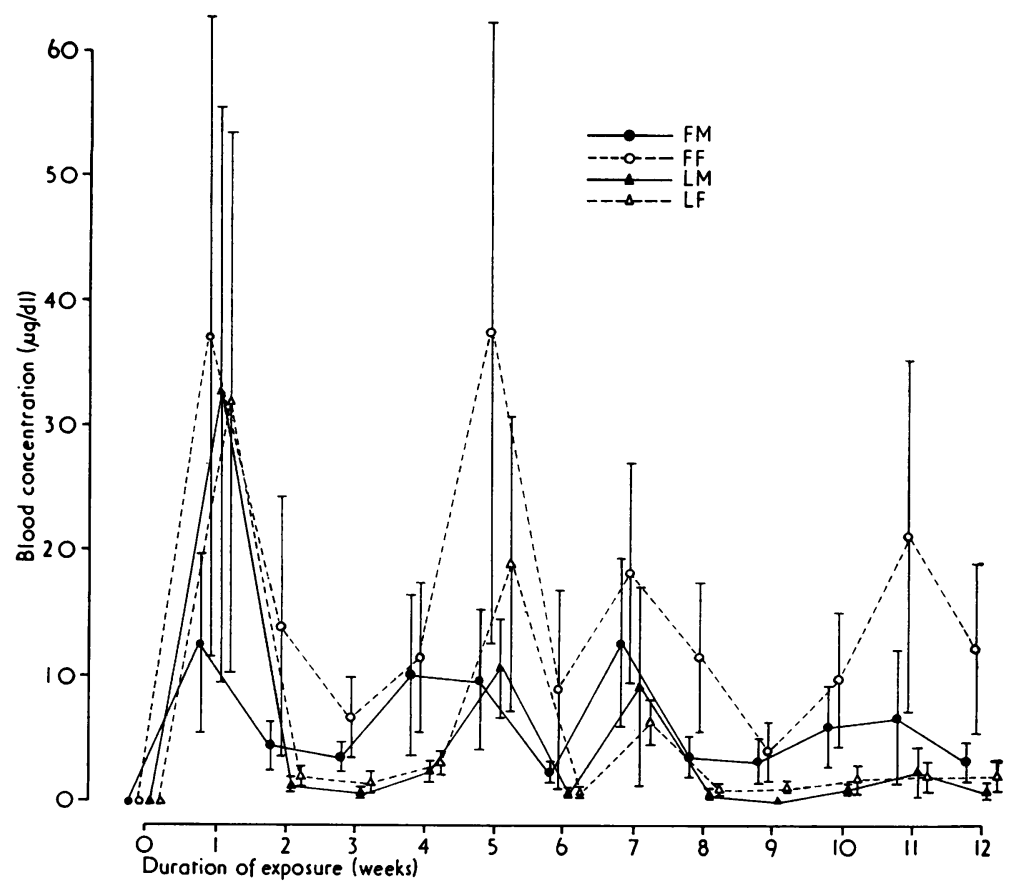

FIG. 3. Blood benzene level about 22 hours after the daily exposure. The vertical line represents the mean value $\pm \mathrm{SD}$.

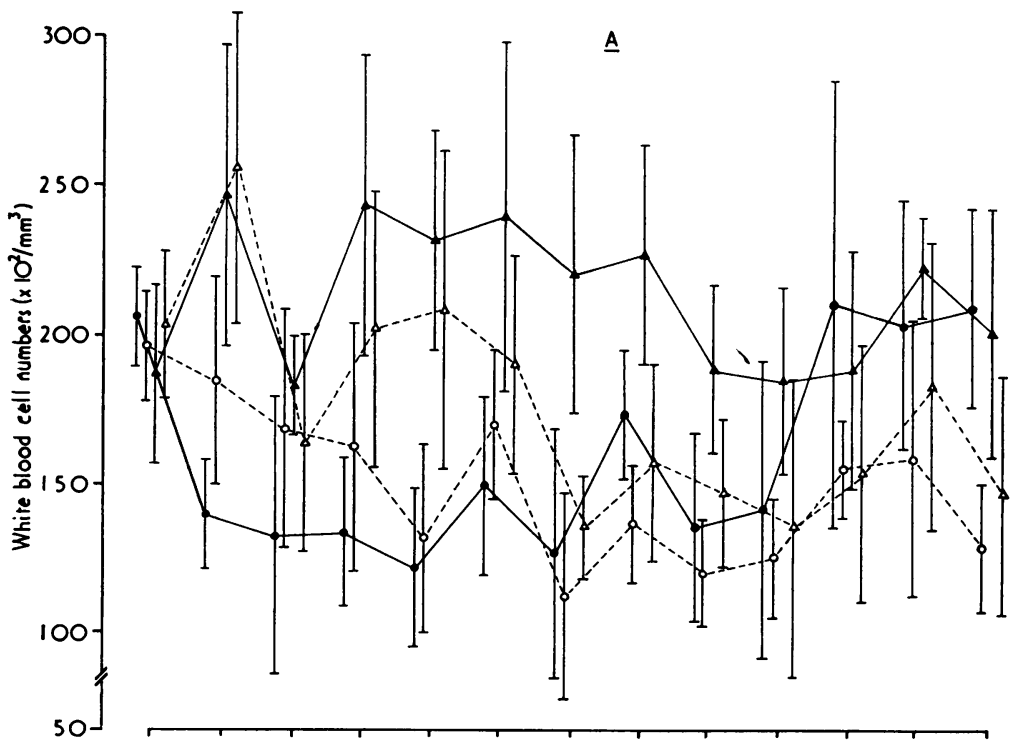

FIG. 4. Changes in blood cell numbers. A: White blood cell. B: Red blood cell. The vertical line represents the mean value $\pm \mathrm{SD}$.

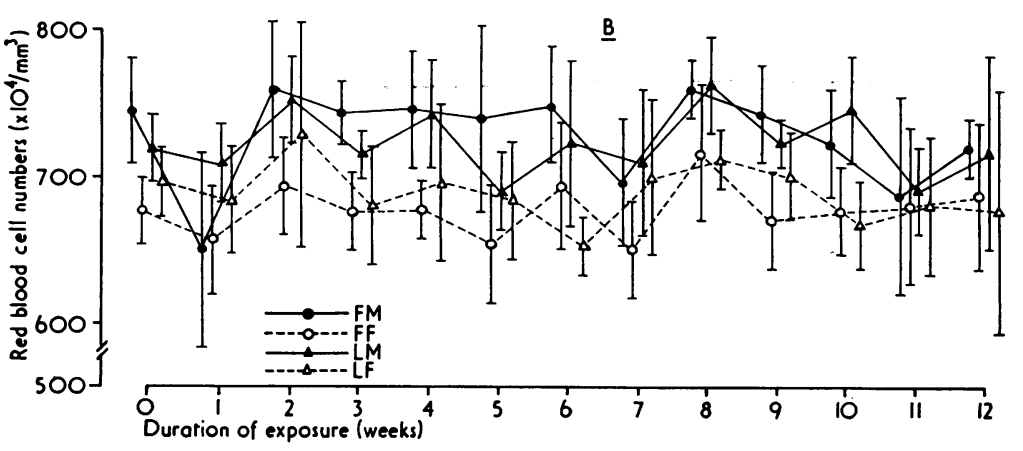


Red and white blood cell counts Red and white blood cell numbers are shown in Fig. 4; there was a pronounced fluctuation in number of the white blood cells in all the groups, particularly in the LM and LF groups. A distinct decrease, however, in the white blood cell count for three to four consecutive weeks, which is a typical symptom of chronic benzene intoxication (Browning, 1965), was noted at first only in the FM and FF groups, which had a larger body fat content as well as a higher benzene level in the blood, although a similar decrease was also observed later in the LF group. This result indicates that, with the fat tissue being increased, male rats which have been reported to have a considerable resistance will be susceptible to benzene intoxication, and also that female rats which have been reported to have a higher degree of susceptibility, with the fat tissue being lowered, will relatively be resistant to benzene intoxication.

Relationship between blood level of benzene and blood cell counts When the benzene level was high in blood, white blood cells tended to increase and red cells to decrease in count. On the other hand, when the benzene level was low, white blood cells tended to decrease and red cells to increase (Figs 3 and 4). In other words, there existed a positive correlation between the benzene concentration and the white blood cell count, while a negative correlation between the concentration and the red cell count. The coefficients of correlation were as follows: the blood benzene level $v$. the white blood cell count; 0.08 for FM, 0.21 for FF, $0.45^{*}$ for LM, and $0.42^{*}$ for LF. The blood benzene level $v$. the red blood cell count: -0.21 for FM, $-0.39^{*}$ for FF, $-0.33^{*}$ for $L M$, and -0.22 for LF. The asterisk indicates that there is a significant correlation at $P=0.01$ $(n=60)$. No reason has been established for these results.

\section{Experimental human exposure to benzene}

Benzene concentrations both in blood and end-tidal air with the lapse of time during and after the inhalation were plotted on semi-log paper against time (Fig. 5). The blood concentrations while inhaling were always higher in the males than in the females $(P<0.005)$. This result, however, does not necessarily mean that the amount of benzene absorbed in the body was larger in the males than in the females, since the volume of benzene distribution in the females is much larger than that in the males. This point will be discussed in more detail in the Discussion section.

After the cessation of inhalation, the concentrations of benzene both in blood and end-tidal air began to decrease rapidly, with different rates

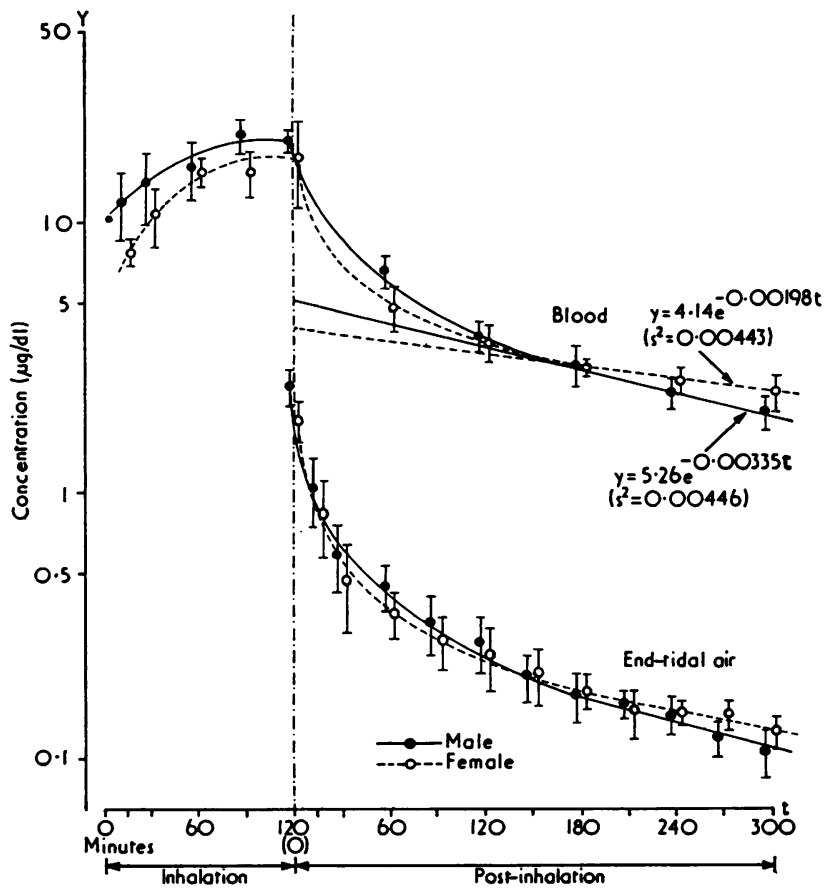

FIG. 5. Saturation and desaturation curves of benzene obtained from a human experimental exposure. The vertical line represents the mean value \pm SD. $\left(s^{2}=\right.$ mean square of deviation from linear regression) 
between the males and females, and after four hours the concentration was higher in the females than in the males.

It seemed possible that the latter half of the decay curve in Fig. 5, that is, the curve over a period that starts three hours after the cessation of inhalation, would be expressed as a straight line. The slope of the straight lines determined by the method of least squares was -0.00335 and -0.00198 in the males and females, respectively. The difference between these slopes was found to be significant $(P<0.05)$ by the analysis of covariance (Snedecor, 1956). The following formulae were hence established to express the time-course of desaturation processes in this period:

For the males $\quad \mathrm{y}=5 \cdot 26 \mathrm{e}^{-0.00335 t}, \ldots$ (1) and for the females $y=4 \cdot 14 \mathrm{e}^{-0.00198 t}, \ldots$ (2)

where $y$ is the blood concentration of benzene in $\mu \mathrm{g} / \mathrm{dl}$ and $\mathrm{t}$ is the time in minutes from 180 to 300 . These formulae show that there exists a tendency in human beings for the absorbed benzene to remain for a longer time in females than in males.

\section{Discussion}

Sato et al. (1974) reported from the mathematical analysis of the desaturation processes of benzene and toluene inhaled in men that the rate constant, $\alpha$, at which these chemicals disappear from a living body over a period which starts three hours after the cessation of inhalation can be expressed in the following equation:

$$
\alpha=\frac{\lambda_{1} \mathrm{k}_{1}+\mathrm{k}_{2}}{\lambda_{2} \mathrm{~V}_{\mathrm{F}}},
$$

where $k_{1}$ is the alveolar ventilation, $\mathbf{k}_{2}$ the metabolic clearance, $\lambda_{1}$ the air-blood partition coefficient, $\lambda_{2}$ the fat-blood partition coefficient, and $V_{F}$ the volume of fat tissue.

Equation (3) implies that the rate constant for the elimination of the vapours is largely dependent on the bulk of body fat tissue. That is, the larger the bulk of fat tissue is, the smaller the rate constant is, hence the vapours remain in the body longer. This prediction is consistent with the present studies with rats and human volunteers (Figs 2, 3, and 5).

As is clear from equation (3), the metabolic clearance also influences the rate of disappearance of benzene. It is a well-known fact that the activity of drug-metabolizing enzyme in liver microsomes is two to three times higher in male rats than in female ones (Quinn et al., 1958; Booth and Gillette, 1962; Kato, 1974). The FF group, which had a smaller body fat content, showed always a higher blood level of benzene than the FM, which had a larger body fat content (Fig. 3). This finding may be explained from this sex difference in the enzyme system.
It has been reported that the activity of this enzyme system varies with the nutritional state, such as starvation (Dixon, Shultice, and Fouts, 1960; Kato and Gillette, 1965) and deficiency in protein (McLean and McLean, 1966; Seawright and McLean, 1967). As for the rapid disappearance of benzene in the LM and LF groups (Figs 2 and 3), for which the feed was limited, it may be a problem whether this feeding condition could enhance the activity of the enzyme system or not. Starvation of rats for as little as 16 hours, a condition which is similar in our present study, has been reported by Roth and Bukovsky (1961) to deplete the liver glycogen, reducing the enzyme activity in rat liver to almost zero. The amount of feed, $20 \mathrm{~g} /$ day, is by no means deficient for nutrient requirements of rats, since the body weight in the feed-restricted groups continued to increase, even though slightly, throughout the experimental period (Fig. 1). It is difficult, therefore, to presume that the restricted feed in the LM and LF groups might have enhanced the enzyme activity to such an extent as to explain the rapid elimination of benzene in these groups. Accordingly, it may be concluded that the difference of the blood benzene level between the FM and LM, and also between the FF and LF groups may have been largely due to the difference of the body fat content between these groups.

In the experimental human exposure, the concentration of benzene in blood during exposure was consistently lower in the females than in the males (Fig. 5). The human body fat content is much larger in females than in males (Keys and Brožek, 1953), the fact which indicates that for such a substance as benzene, which has a high affinity to the fat tissue, the distribution volume is much greater in females than in males (Sato et al., 1974). Therefore, it is reasonable to presume that the amount of the absorbed benzene was not smaller in the females than in the males. The uptake rate for benzene in females was also reported to be higher than that in males by Nomiyama and Nomiyama (1969). Since there is no sex difference in the air-blood partition coefficient for benzene (Sato, Fujiwara, and Hirosawa, 1972), this sex difference in the uptake rate implies nothing but the sex difference in the volume of distribution, that is, in the volume of fat tissue.

It is undecided whether the dysfunction of the haematopoietic system in chronic benzene intoxication is induced by benzene itself or by its metabolites. Although a recent finding that the pretreatment of rats with phenobarbital has protected against benzene-induced bone marrow damage seems to be in favour of the proposition that benzene itself is the toxic agent (Ikeda and Ohtsuji, 1971), it does not necessarily preclude the possibility that benzene exerts its effect through the formation of an unknown active metabolite (Gillette, Mitchell, and Brodie, 
1974). Whatever the primary cause of dysfunction, the lower rate of elimination of the absorbed benzene may result in a more prolonged contact of the toxic agent with the action site. As the bone marrow, where the action of benzene is assumed to take place, has a large fat content, it retains about 20 times as much benzene as the blood when the equilibrium throughout the body is established (Schrenk et al., 1941; Sato et al., 1974). It should be remarked here that the bone marrow is exposed to quite a high concentration of benzene even when the concentration is low in the blood.

Since the activity of drug-metabolizing enzyme in male rats has been reported to be much higher than in female ones, the sex difference in the susceptibility observed in rats may partly be explained by this sex difference in the enzyme activity. This is supported by the present finding that the rats in LF group with their diminished fat tissue content showed, in a later course of experiment, a pronounced decrease in white blood cell numbers (Fig. 4). It is doubtful, however, whether such an outstanding sex difference in the enzyme activity as reportedly observed in rats is also present in human beings.

The equation (3) can be written as follows:

$$
\mathrm{k}_{2}=\alpha \lambda_{2} \mathrm{~V}_{\mathrm{F}}-\lambda_{1} \mathrm{k}_{1} \text {. }
$$

The metabolic clearances, $\mathrm{k}_{2}$, both in the males and females, were calculated from the equation (1), (2), and (4) on the assumption that $k_{1}$ and $V_{F}$ were $5.61 / \mathrm{min}$ and 10.01 in the males and $4.81 / \mathrm{min}$ and 15.01 in the females, respectively. As for $\lambda_{1}$ and $\lambda_{2}$, the values reported by Sato et al. (1974), 0.13 and 52.6, respectively, were used. The resultant values were $1.03 \mathrm{l} / \mathrm{min}$ in the males and $0.94 \mathrm{l} / \mathrm{min}$ in the females. Accordingly, it may well be said that there hardly exists in human beings such a remarkable sex difference as in rats, although a considerable error may be contained in the calculation of $k_{2}$ using $k_{1}$ and $V_{F}$ which are not measured directly. This agrees well with the report (Kato, 1974) that human beings show no sex difference in the activity of drugmetabolizing enzyme systems. Therefore, the slower elimination of benzene in the females (Fig. 5) can be said to be due primarily to the bulky distribution of body fat tissue in that sex.

From the observation that the susceptibility of male rabbits, castrated and administered oestradiol, was raised to a similar extent to that in the females, Hirokawa (1955) concluded that the follicular hormone might play a major role in the manifestation of the sex difference in the susceptibility to benzene. It is unknown, however, by what mechanisms such treatments as castration and oestradiol administration enhanced the susceptibility of the male rabbits. It is well recognized in rats that androgen enhances the activity of drug-metabolizing enzyme systems and that oestrogen is competitive with that action of androgen (Kato, Takanaka, and Takayanagi, 1968). In the rabbits, too, the administration of oestradiol after castration might have enhanced the susceptibility of the male rabbits through changing the activity of this enzyme system. It must be borne in mind, however, that castration or oestrogen administration feminizes the body proportions of male animals and increases the mass of body fat tissue.

Consequently, it is possible to conclude that the human female with her relatively large body fat tissue may show an inherent disposition to be susceptible to such a chemical as benzene which has a high affinity with the fat tissue.

\section{References}

Booth, J. and Gillette, J. R. (1962). The effect of anabolic steroids on drug metabolism by microsomal enzymes in rat liver. Journal of Pharmacology and Experimental Therapeutics, 137, 374-379.

Browning, E. (1965). Toxicity and Metabolism of Industrial Solvents, pp. 3-31. Elsevier, Amsterdam, London, New York.

Dixon, R. L., Shultice, R. W., and Fouts, J. R. (1960). Factors affecting drug metabolism by liver microsomes. IV. Starvation. Proceedings of the Society for Experimental Biology and Medicine, 103, 333-335.

Gillette, J. R., Mitchell, J. R., and Brodie, B. B. (1974). Biochemical mechanisms of drug toxicity. Annual Review of Pharmacology, 14, 271-288.

Hanson, N. W., Reilly, D. A., and Stagg, H. E. (1965). The Determination of Toxic Substances in Air-A Manual of ICI Practice, revised edition, pp. 29-31. Heffer, Cambridge.

Hirokawa, T. (1955). Studies on the poisoning by benzol and its homologues. IV. Experimental studies on the sexual differences of blood picture. Japanese Journal of Medical Sciences and Biology, 8, 275-281.

- (1960). Quelques observations sur l'intoxication benzénique. Archives des Maladies Professionnelles, de Médecine du Travail et de Sécurité Sociale, 21, 46-49.

Ikeda, M. (1964). Enzymatic studies on benzene intoxication. Journal of Biochemistry (Tokyo), 55, 231-243.

__ and Ohtsuji, H. (1971). Phenobarbital-induced protection against toxicity of toluene and benzene in the rat. Toxicology and Applied Pharmacology, 20, $30-43$.

Kato, R. (1974). Sex-related differences in drug metabolism. Drug Metabolism Reviews, 3, 1-32.

- _ and Gillette, J. R. (1965). Effect of starvation on NADPH-dependent enzymes in liver microsomes of male and female rats. Journal of Pharmacology and Experimental Therapeutics, 150, 279-284.

_- Takanaka, A., and Takayanagi, M. (1968). Studies on mechanism of sex difference in drug-oxidizing activity of liver microsomes. Japanese Journal of Pharmacology, 18, 482-489.

Keys, A. and Brožek, J. (1953). Body fat in adult man. Physiological Reviews, 33, 245-298.

Levy, G. and Gibaldi, M. (1972). Pharmacokinetics of 
drug action. Annual Review of Pharmacology, 12, 85-98.

McLean, A. E. M. and McLean, E. K. (1966). The effect of diet and 1,1,1-trichloro-2,2-bis-(p-chlorophenyl) ethane (DDT) on microsomal hydroxylating enzymes and on sensitivity of rats to carbon tetrachloride poisoning. Biochemical Journal, 100, 564-571.

Nomiyama, K. and Nomiyama, H. (1969). Sex difference in benzene uptake in man. Industrial Health (Kawasaki) 7, 86-87.

Quinn, G. P., Axelrod, J., and Brodie, B. B. (1958). Species, strain and sex differences in metabolism of hexobarbitone, amidopyrine, antipyrine and aniline. Biochemical Pharmacology, 1, 152-159.

Roth, J. S. and Bukovsky, J. (1961). Studies on an Ndemethylating system in rat liver microsomes. Journal of Pharmacology and Experimental Therapeutics, 131, 275-281.

Ruthbun, E. N. and Pace, N. (1945). Studies on body composition. I. The determination of total body fat by means of the body specific gravity. Journal of Biological Chemistry, 158, 667-676.

Sato, A. (1968). Gas chromatographic determination of benzene and toluene in expired air. Medical Journal of Shinshu University, 13, 167-174.

(1971). Gas chromatographic determination of benzene, toluene and m-xylene in blood by an equilibration method (in Japanese). Japanese Journal of Industrial Health, 13, 173-179.
- Fujiwara, Y., and Hirosawa, K. (1972). Solubility of benzene, toluene and $\mathrm{m}$-xylene in blood (in Japanese). Japanese Journal of Industrial Health, 14, 3-8.

—, Nakajima, T., and Fujiwara, Y. (1975). Determination of benzene and toluene in blood by means of syringe-equilibration method using a small amount of blood. British Journal of Industrial Medicine, 32, 210-214.

,,--- and Hirosawa, K. (1974). Pharmacokinetics of benzene and toluene. Internationales Archiv für Arbeitsmedizin, 33, 169-182.

Schrenk, H. H., Yant, W. P., Pearce, S. J., Patty, F. A., and Sayers, R. R. (1941). Absorption, distribution and elimination of benzene by body tissues and fluids of dogs exposed to benzene vapor. Journal of Industrial Hygiene and Toxicology, 23, 20-34.

Seawright, A. A. and McLean, A. E. M. (1967). The effect of diet on carbon tetrachloride metabolism. Biochemical Journal, 105, 1055-1060.

Snedecor, G. W. (1956). Statistical Methods, 5th ed., pp. 394-412. Iowa State College Press, Ames, Iowa.

Received for publication 20 March 1975

Accepted for publication 18 June 1975 